\title{
PERKEMBANGAN PENDIDIKAN FORMAL DI SAMBAS PADA MASA PEMERINTAHAN SULTAN MUHAMMAD MULIA IBRAHIM TSAFIUDDIN (1931-1943)
}

\author{
Thoriq \\ Madrasah Aliyah Gerpemi Tebas \\ Email: ${ }^{1}$ thoriqrusdi@yahoo.com
}

\begin{abstract}
Abstrak
Tujuan penelitian ini adalah untuk melihat pendidikan Islam pada masa pemerintahan Sultan Muhammad Mulia Ibrahim Tsafiuddin tahun 1931-1943, pengaruh Belanda terhadap pendidikan di Sambas pada masa pemerintahan Sultan Muhammad Mulia Ibrahim Tsafiuddin tahun 1931-1943, dan sistem pendidikan Madrasah Al-Sultaniyah. Penelitian menggunakan metode sejarah kritis yang terdiri dari empat langkah, yaitu heuristik, kritik sumber, interpretasi dan historiografi. Hasil penelitian menunjukkan bahwa Pendidikan Islam pada masa pemerintahan Sultan Muhammad Mulia Ibrahim Tsafiuddin adalah berlanjutnya pendidikan Madrasah Al-Sultaniyah yang masih berorientasi dalam pendidikan agama dan berkembang menjadi Tarbiyatul Islam. Pendidikan Islam di Sambas mendapat pengaruh Belanda terlihat Sekolah Tabiyatul Islam memasukkan semua pelajaran Holland Inlandsche School (HIS) dalam kurikulumnya. Ilmu pengetahuan modern, terutama bahasa Belanda yang diterapkan di sekolah Tarbiyatul Islam dipandang sebagai alat untuk mengejar kemajuan. Sistem pendidikan formal di Sambas melalui Madrasah Al-Sultaniyah mauoun Tarbiyatul Islam menggabungkan pendidikan Islam dan Pendidikan Belanda.
\end{abstract}

Kata Kunci: pendidikan, Sultan Mulia Ibrahim Tsafiuddin, Sambas

\begin{abstract}
The aim of this research is to find out the islamic education in era of Sultan Muhammad Mulia Ibrahim Tsafiuddin in 1931-1943, the influences of Netherland to the education in Sambas while the government of Sultan Muhammad Mulia Ibrahim Tsafiuddin in 1931-1943, and the system of education Madrasah Al-Sultaniyah. The methods of this research is a historical research. The methods of the research is descriptive-analitic includes four stages; heuristic, verification, interpretation, and historiography. The results of this research show if islamic education in era of Sultan Muhammad Mulia Ibrahim Tsafiuddin is the continous of the education Madrasah Al-Sultaniyah with the orientation in education of religion and developing to be Tarbiyatul Islam. Islamic education in Sambas gain the influences from Netherland, we can see from Tarbiyatul Islam included all of studied from Holland Inlandsche School (HIS) in their curriculum. The modern science, especially Dutch language in Tarbiyatul Islam seeing as a tool for gain the significant progress. The formal system of education in Sambas through Madrasah Al-Sultaniyah or Tarbiyatul Islam combining islamic education and Dutch education.
\end{abstract}

Keywords: education, Sultan Mulia Ibrahim Tsafiuddin, Sambas

\section{PENDAHULUAN}

Pada masa kolonial Belanda di Indonesia banyak daerah yang mengalami ketertinggalan tidak terkecuali Sambas. Sultan Muhammad Ali Tsafiuddin II 
melihat pentingnya pendidikan untuk mengentaskan masyarakat Sambas dari ketertinggalan dengan mendirikan madrasah Assultaniah. Madsrasah tersebut hanya mengajarkan ilmu agama, karena agama menjadi landasan hidup masyarakat Sambas. Setelah Sultan Muhammad Ali Tsafiudin II wafat tanggal 9 Oktober 1926, pemerintahan dilanjutkan oleh majelis Kesultanan untuk melaksanakan tugas-tugas kesultanan Sambas dikarenakan Raden Mulia Ibrahim masih berusia sangat muda. Setelah dewasa pemeerintahan diserahkan kepada Sultan Mulia Ibrahim Tsafiudin yang merupakan lulusan dari sekolah OSVIA (Opleiding School Voor Inlandsche Ambtenaar) Banten.

Sebagai seorang Sultan yang menggantikan Raden Muhammad Ali Tsafiuddin II beliau tidak hanya fokus dalam pemerintahan, pembangunan, pertanian, selain itu Sultan Muhammad Mulia Ibrahim Tsafiuddin juga melanjutkan lembaga pendidikan yang sebelumnya telah dibangun sejak didirikannya madrasah Assultaniah oleh Sultan Muhammad Tsafiuddin II. Pada waktu itu yang diajarkan masih 100\% agama.

Pertama-tama pendidikan ini dimaksudkan untuk memberikan pendidikan kepada kaum kerabat saja, tetapi lama kelamaan meluas sampai anak-anak kaulanya dikarenakan Pendidikan merupakan salah satu faktor sosial yang dapat mempengaruhi tingkat perkembangan suatu masyarakat dalam suatu wilayah, dalam hal ini Sambas khususnya. Melalui pendidikan baik formal maupun non formal seseorang akan mendapat pengetahuan serta dapat mengembangkan keterampilan ataupun potensi yang dimilkinya. Dengan demikian seseorang yang mempunyai potensi serta keahlian khusus diharapkan dapat mengembangkan segala sumber yang tersedia di daerahnya untuk mewujudkan kesejahteraan penduduk untuk kepentingan dan perkembangan bersama.

Bahasa pengantar dalam Masdrasah Al-Sultaniah masih dipergunakan bahasa melayu kuno dengan huruf arab melayu. Dan mengenai tempatnya pun belum berwujud seperti sekolah-sekolah pada lazimnya tetapi masih ada didalam istana. Jadi pengelolaan lembaga pendidikan ini sepenuhnya masih ditangan Sultan. Baru dalam perkembangannya Madrasah Al-Sultaniyah semakin 
berkembang dikarenakan mulai ramai berdirinya Volkschool hampir di seluruh Kalimantan Barat.

Madrasah Al-Sultaniah juga mulai menyesuaikan diri dengan Volkschool tersebut dengan merubah sistem maupun metode pengajarannya antara lain dengan menambah mata pelajaran yang bersifat umum, antara lain mulai diajarkannya berhitung, menulis huruf latin, membaca dan sebagainya, dengan tetap berpedoman pada ajaran agama Islam yang menjadi pokok ajaran. Eksistensi dan pengaruh Belanda terhadap pendidikan Madrasah Al-Sultaniyah menjadi bahasan untuk dikaji lebih dalam.

\section{METODE}

Penelitian ini menggunakan metode penelitian sejarah Metode penelitian sejarah merupakan proses meneliti dan menganalisis secara sistematis dan kritis keseluruhan perkembangan masyarakat serta kemanusiaan melalui rekaman dan peninggalan masa lampau (Gootschalk, 2008:39). Menurut Nugroho Notosusanto, tahapan penelitian sejarah terdiri dari heuristik, verifikasi, interpretasi dan penulisan (Nugroho Notosusanto, 1971: 35).

\section{Heuristik}

Heuristik adalah proses mencari untuk menemukan sumber-sumber (Aam Abdullah, 2012: 29). Usaha merekonstruksi masa lampau tidak mungkin dilakukan tanpa tersedianya sumber-sumber atau bukti-bukti sejarah. No record, no history. Sumber primer dalam penelitian ini adalah (1)Muhammad Sabirin Ag, Ba yang pada saat itu merupakan salah satu murid/ siswa yang turut serta dalam merasakan pendidikan pada masa pemerintahan Sultan Muhammad Mulia Ibrahim Tsafiuddin Sultan yang ke-15 Sambas tahun 1931-1943, (2)Abdul Mu'in Ikram, Mereka merupakan sejarawan Sambas sekaligus saksi mata yang pernah mengenyam pendidikan pada masa pemerintahan Sultan Muhammad Mulia Ibrahim Tsafiuddin pada tahun 1931-1943. Adapun sumber benda yang masih ada sampai sekarang adalah sekolah yang masih kokoh berdiri di Sambas adalah yaitu Tarbiyatul Islamiyah sebagai bukti bahwa pendidikan sudah dibangun pada masa 
Sultan Muhammad Mulia Ibrahim Tsafiuddin yang memerintah Sambas tahun 1931-1943.

\section{Verifikasi}

verifikasi adalah tahapan yang dilakukan dalam proses pemeriksaan dan pengujian terhadap informasi maupun sumber-sumber sejarah yang telah ditemukan untuk mendapatkan suatu kebenaran dari sebuah peristiwa. Verifikasi dilakukan melalui dua tahap, yaitu kritik ekstern dan kritik intern.

\section{Interpretasi}

Tahapan interpretasi merupakan tahap yang banyak terjadinya subjektivitas yang dilakukan peneliti. Subjektivitas yang dimaksud adalah peneliti menafsirkan fakta-fakta sejarah sesuai dengan keinginannya atau menitikberatkan pada pada kelompok-kelompok tertentu. Tetapi dalam penelitian sejarah subjektivitas itu adalah hak sejarawan. Sejarawan memiliki pandangan tersendiri bagaiman ia melihat suatu peristiwa sejarah melalui fakta-fakta sejarah yang telah ditetapkan. Agar tidak terjadinya subjektivitas yang tinggi sejarawan tetap ada di bawah bimbingan metodologi sejarah. Metodologi mengharuskan sejarawan mencantumkan sumber datanya (Suhartono W. Pranoto, 2006: 55).

\section{Historiografi}

Historiografi adalah penyajian fakta-fakta sejarah yang telah melalui langkah-langkah heuristik, kritik sumber, interpretasi yang kemudian historiografi. Helius Sjamsuddin (2012: 121) menyatakan bahwa "historiografi bukan hanya keterampilan teknis penggunaan kutipan-kutipan dan catatan, tetapi yang terutama penggunaan pikiran-pikiran kritis dan analisisnya karena pada akhirnya harus menghasilkan suatu sintetis dari seluruh hasil penelitian atau penemuan dalam suatu penulisan yang utuh".

Penulisan sejarah perkembangan pendidikan formal pada masa pemerintahan Sultan Muhammad Mulia Ibrahim Tsafiuddin adalah sebagai alat komunikasi yang disampaikan peneliti dari apa yang didapat selama melakukan 
penelitian. Penulisan sejarah harus objektif dan tidak mengandung subjektivitas dalam penulisannya, agar tulisan yang dihasilkan mengandung kebenaran sejarah yang dapat dipertanggungjawabkan. Selain menngunakan sumber sejarah yang valid dalam penulisan sejarah, selain itu juga diperlukan bahasa yang mudah dimengerti oleh pembaca sehingga hasil penelitian benar-benar dapat disampaikan kepada pembaca.

\section{HASIL DAN PEMBAHASAN}

\section{Pendidikan Islam Pada Masa Pemerintahan Sultan Muhammad Mulia Ibrahim} Tsafiuddin (1931-1943)

Pendidikan di Kerajaan Sambas pada masa kolonial dijalankan oleh Kerajaan Sambas dengan Pemerintah Belanda karena pengaruh Belanda cukup kuat serta kurikulum Belanda sangat dominan pada waktu itu. Pendidikan formal berbentuk madrasah dan sekolah di Sambas yang pertama kali didirikan pada masa pemerintahan Sultan Muhammad Tsafiuddin II. Perkembangan sekolah yang semakin merakyat dalam batas yang cukup jauh telah merangsang kalangan Islam untuk menyadari akan perlunya pendidikan, jika mereka tidak ingin tertinggal. Dalam hal ini kalangan Islam melihat bahwa diskriminasi untuk mendapat kesempatan pendidikan sangat tampak dalam politik dan kebijakan pemerintah Hindia-Belanda.

Menurut Erwin Mahrus (2013:157-158) perkembangan pendidikan di Kesultanan Sambas memiliki beberapa fase berikut ini. Pertama, pendidikan di lingkungan keluarga. Pendidikan di lingkungan keluarga diberikan dalam bentuk pelajaran membaca al-Qur'an. Kedua, pada tahap ini adanya pengakuan anggota masyarakat atau lingkungan masyarakat terhadap kealiman dan kesalehan seorang ustad atau syekh, sehingga anggota mengirimkan anaknya untuk memperdalam ilmu. Pada tahap ini anak-anak yang telah meningkat remaja diajari dasar-dasar ilmu nahwu dan saraf.

Ketiga, pendidikan Istana. Ketika penguasa ke-8 Kesultanan Sambas, Mahurum Anom yang bergelar Sultan Muhammad Ali Tsafiuddin (berkuasa 1813-1826), mulai membangun institusi keagamaan Islam di Istana dengan 
melantik H. Nuruddin Mustafa sebagai Imam KesultananDengan demikian perkembangan berikutnya istana dijadikan lembaga pendidikan dikalangan keluarga elit penguasa selain mesjid.

Keempat, berdirinya lembaga pendidikan formal berbentuk madrasah dan sekolah. Oleh sultan Muhammad Tsafiuddin II cikal bakal dari lembaga pendidikan istana tadi dikembangkan menjadi sebuah pendidikan formal diberi nama madrasah Al-Sultaniayah pada tahun 1916. Kemudian selanjutnya Madrasah Al-Sultaniyah diganti namanya menjadi Tarbiyatul Islam.

Akan tetapi awal berdirinya Pendidikan di Sambas tidak langsung menyentuh kalangan-kalangan masyarakat menengah ke bawah melainkan diperuntukkan hanya orang-orang yang mampu, orang terpandang dan dianggap berpengaruh yang dapat mengenyam pendidikan pada masa itu. Namun setelah berkembangnya pendidikan di Sambas, semua kalangan masyarakat dapat mengenyam pendidikan formal. Hal tersebut tampak setiap masuk tahun ajaran baru diumumkan lewat transportasi sungai yang menyuarakan "hallo-hallo, sekolah-sekolah, daftarkan anak-anak".

Madrasah As-Sultaniah tersebut adalah sekolah yang dididirkan di lingkungan Istana Al-Watzikubillah Sambas yang pengajarannya dilakukan dalam lingkungan Istana. Awal mula berdirinya pendidikan As-Sultaniah yang letaknya di Istana khusus untuk menerima keluarga-keluarga Sultan Sambas dan orang terkemuka di Sambas seperti kalangan kaum ningrat, keturunan Raja di Sambas dan orang kenamaan ataupun orang yang berada yang diterima di sekolah tersebut.

Layaknya sekolah, Madsarah Sultaniah ini juga memiliki pelajaranpelajaran yang dimuat dalam belajar-mengajar. Materi pelajaran Madrasah Sultaniah ini meliputi ilmu tauhid, fiqih, tafsir, hadis, bahasa arab (ma'ani, bayan dan saraf) (Gustriyeni 2014 : 60). Kemudian menurut Urai Riza Fahmi mengatakan "yang diajarkan di Madrasah As-Sultaniah yakni kurikulum agama Islam antara lain: Fiqih, Tauhid, Sejarah Islam. Jika melihat kurikulum yang diterapkan di Madrasah Al-Sultaniah ini corak pendidikan agama masih 
mendominasi materi pelajarannya, sehingga Madrasah ini dikenal dengan sebutan sekolah arab.

Sekolah As-Sultaniah berubah menjadi sekolah Tarbiyatul Islam pada tahun 1936 serta lokasi yang tidak lagi berada di lingkungan Istana AlWatzikubillah. Sekolah Tarbiyatul Islam menitikberatkan pelajaran utamanya banyak pelajaran agama. Sekolah Tarbiyatul Islam Sambas bergelar pada waktu itu sekolah arab dikarenakan pelajaran-pelajarannya banyak yang menggunakan bahasa arab akan tetapi bahasa pengantarnya tetap menggunakan bahasa daerah Sambas namum banyak pelajaran yang menggunakan bahasa arab. Kemudian menurut Munziri Matsum yang mengatak bahwa "pendidikan di Tarbiyatul Islam banyak pendidikan agama, kelas satu sampai dengan kelas enam banyak menggunakan bahasa arab sehingga sekolah tersebut disebut Sekolah Arab”.

\section{Pengaruh Belanda Terhadap Pendidikan Di Sambas Pada Masa Pemerintahan Sultan Muhammad Mulia Ibrahim Tsafiuddin (1931-1943)}

Pada tahun 1848 pemerintah Belanda mengharuskan pemerintah Hindia Belanda harus menyelenggarakan pendidikan formal. Kemudian pemerintah Hindia Belanda dengan Staatsblad tahun 1893 nomor 125 mengeluarkan peraturan yang membagi sekolah di Indonesia menjadi 2 bagian, yaitu : 1) Sekolah kelas satu, sekolah ini khusus untuk anak-anak priyai dan kaum terkemuka (aristokrat). 2) Sekolah-sekolah kelas dua, sekolah ini diperuntukkan bagi anak-anak rakyat jelata (Fasifikus Ahok, dkk, 1980 : 47-48).

Pendidikan Belanda telah masuk di Kesultanan Sambas yakni pada masa pemerintahan Sultan Sambas yang ke-13 yakni Sultan Muhammad Tsafiuddin II. Belanda mendirikan sekolah Bumu melalui Besluit Gubernument Belanda pada tahun 1903. Sekolah kelas II lamanya tiga tahun, yakni kelas 1, 2, dan 3" dan semakin banyak rakyat yang ingin memasukkan anaknya ke sekolah, sehingga sekolah tersebut tidak dapat lagi menampung siswa. Untuk mengatasi hal tersebut dengan Besluit Gubernument Belanda pada tanggal 1 Desember 1910 didirikan lagi sebuah sekolah Special School yang kemudian pada tahun 1915 berubah menjadi HIS (Urai Riza Fahmi, 2012:48) dan selama sekolah yang berdiri ada izin 
Gubernument Belanda berarti sekolah tersebut sudah ada campur tangan Belanda karena Belanda juga takut seandainya tiba-tiba membangun sebuah pendidikan atau sekolah untuk nantinya memberontak jadi harus izin dan dibawah pengawasan Belanda.

Sekolah Tabiyatul Islam memasukkan semua pelajaran Holland Inlandsche School (HIS) dalam kurikulumnya. Ilmu pengetahuan modern, terutama bahasa Belanda yang diterapkan di sekolah Tarbiyatul Islam dipandang sebagai alat untuk mengejar kemajuan. Bahasa Belanda telah membukakan jalan bagi pemuda dan masyarakat Sambas untuk mengakses pendidikan yang lebih tinggi.

Dalam Statuten (Anggaran Dasar) Tarbiyatul Islam disebutkan bahwa salah satu tujuan perkumpulan Tarbiyatul Islam adalah "membangun dan membantu sekolah-sekolah yang diberikan dasar-dasar pelajaran agama Islam dan ilmu-ilmu yang biasa diajarkan di sekolah-sekolah seperti Holland Inlandsche School (HIS) dan sebangsanya". Untuk mendukung cita-cita pendidikannya tersebut, lembaga yang berdiri tanggal 1 Juli 1936 ini mulai memasok tenaga pendidikyang ahli dan berdiploma pemerintah, seperti Mursyid Idris (Gustriyeni, 2014: 69).

Madrasah yang berdiri pada tahun 1936 ini lama pelajaran lima tahun (5 kelas) dan ditambah satu tahun lagi untuk kursus pelajaran agama. Yang diterima masuk Madrasah ini adalah tamatan SR 5/6 tahun. Ketua pengurus Madrasah ini adalah H. M. Basuni Imran seorang ulama besar di Sambas dan ketua Madrasah ialah H. Abd. Rahman. Pelajarannya ialah ilmu-ilmu agama ditambah dengan pengetahuan umum sebagai berikut (Rencana Pelajaran Tahun 1953); nahwu, sharaf, insya', bahasa arab, tafsir hadis, fiqih, ushul, tarikh, berhitung, ilmu bumi, ilmu alam, ilmu tumbuh-tumbuhan, ilmu ukur, kesehatan, akhlak, gerak badan, alQur'an, terjemah (Erwin Mahrus, $2013: 159$ ).

\section{Sistem Pendidikan Al-Sultaniyah dan Tarbiyatul Islamiyah}

Tarbiyatul Islamiyah merupakan perguruan sebagaimana Volkschool dengan pengajaran modern ala barat yang dipadu dengan pengajaran agama Islam 
(Juniar Purba, dkk, 114). Dilihat dari Kurikulumnya, pelajaran-pelajaran yang diajarkan di Madrasah Al-Sultaniah masih mendominasi yakni ajaran agama Islam sehingga nuansa Islam masih sangat kental dalam sistem belajar mengajar di Madrasah Al-Sultaniyah sampai kepada Madrasah Al-Sultaniyah yang terakhir yakni Tarbiyatul Islam. Madrasah As-Sultaniah tersebut adalah sekolah yang didirikan di lingkungan Istana Al-Watzikubillah Sambas yang pengajarannya pun dilakukan dalam lingkungan Istana. Madrasah Al-Sultaniah tersebut didirikan pada tahun 1916. Madrasah As-Sultaniah merupakan gabungan antara kurikulum Belanda dangan kurikulum Islam.

Materi pelajaran Madrasah Al-Sultaniyah ini meliputi ilmu tauhid, fiqih, tafsir, hadis, bahasa arab (ma'ani, bayan dan saraf) (Gustriyeni 2014 : 60). Kemudian menurut Urai Riza Fahmi mengatakan "yang diajarkan di Madrasah As-Sultaniah yakni kurikulum agama Islam antara lain: Fiqih, Tauhid, Sejarah Islam. Sedangkan dalam kurikulum umum antara lain; berhitung). Jika melihat kurikulum yang diterapkan di Madrasah Al-Sultaniah ini corak pendidikan agama masih mendominasi materi pelajarannya.

Meskipun Madrasah Al-Sultaniyah adalah sekolah Islam yang pada waktu itu bergelar sekolah arab akan tetapi proses belajar-mengajar di Madrasah AlSultaniyah sudah menggunakan ruangan kelas sebagai wahana belajarnya serta menggabungkan antara murid laki-laki dan perempuan di dalam satu ruangannya.

Untuk mendukung jalannya pendidikan diperlukan sistem administrasi guna menunjang kelancaran pendidikan yang diselenggarakan untuk menunjang segala keperluan dan fasilitas sekolah atau madrasah. Madrasah Al-Sultaniah yang berdiri padatahun 1916 yang saat itu seluruh pembiayaan dan fasilitas Madrasah Al-Sultaniah tersebut sepenuhnya di bawah otoritas Sultan Muhammad Syafiuddin II. Kemudian sepeninggalnya Sultan Muhammad Syafiuddin II, segala sesuatu yang berkaitan dengan sekolah tersebut diserahkan kepada Sultan Muhammad Ali Syafiuddin II.Setelah meninggalnya Sultan Muhammad Ali Syafiuddin II, maka segala urusan dan kelanjutan pendidikan dan sebagainya pada sekolah tersebut diserahkan kepada Syekh Muhammad Basiuni Imran (Gustriyeni, 2014 : 69). 
Kemudian berdasarkan wawancara dengan Sabirin Abdul Gafar yang mengatakan bahwa "Madrasah Sultaniah oleh Maharaja Imam Muhammad Basuni Imran di pindahkan ke Kampus Angus dengan nama Tarbiyatul Islam”. Setelah perubahan Madrasah Al-Sultaniah menjadi Tarbiyatul Islam Sambas, nama Syekh Muhammad Basiuni Imran masih mewarnai dunia pendidikan di Sambas bahkan sampai masa pemerintahan Sultan Muhammad Mulia Ibrahim Syafiuddin. Hal ini terlihat ketika Tarbiyatul Islam ini dipelopori oleh Syekh Muhammad Basiuni Imran yang sekaligus menjadi Ketua di lembaga pendidikan Islam tersebut pada tahun 1936-1950 (Gustriyeni, $2014: 63$ ).

Di Sekolah Tarbiyatul Islam yang dikelola oleh Maharaja Imam Muhammad Basuni Imran ini ternyata tidak diwajibkan untuk membayar artinya bagi siapa yang tidak mampu tidak perlu bayar, apabila orang yang berada atau mampu cukup member sedikit tambahan karena dana banyak di sokong oleh seniman-seniman yang mengadakan orkes-orkes, sandiwara di desa-desa dan dari hasil tersebut itu pula di sumbangkan ke Tarbiyatul Islam.

\section{SIMPULAN}

Pendidikan Islam pada masa pemerintahan Sultan Muhammad Mulia Ibrahim Tsafiuddin masih kokoh berdiri sebuah sekolah Islam yang bernama Madrasah Al-Sultaniah yang didirikan pada tahun 1916. Madrasah As-Sultaniah merupakan gabungan antara kurikulum Belanda dangan kurikulum Islam. Pendidikan pada masa pemerintahan Sultan Muhammad Mulia Ibrahim Tsafiuddin pada khususnya pendidikan Islam dijalankan oleh seorang Maharaja Imam Sambas K.H Muhammad Basuni Imran yang sejak diangkat oleh Sultan Muhammad Tsafiuddin II menjadi Direktur dan Guru Besar di Madrasah AsSultaniah sejak tahun 1919 sampai dengan tahun 1935 kemudian memindahkan sekolah tersebut ke Kampung Angus dengan nama Tarbiyatul Islam.

Pengaruh Belanda tampak pada permulaan abad ke-19 pemerintah Belanda di Negeri Belanda mulai memikirkan pendidikan dan pengajaran bagi bangsa kita termasuk di Sambas, akibat perubahan ketatanegaraan di Negeri Belanda (Parlemen). Pada tahun 1848 bahwa pemerintah Hindia Belanda harus 
menyelenggarakan sekolah-sekolah untuk memberi pendidikan dan pengajaran kepada bangsa kita. Kemudian pemerintah Hindia Belanda dengan Staatsblad tahun 1893 nomor 125 mengeluarkan peraturan yang membagi sekolah di Indonesia menjadi 2 bagian, yaitu : 1) Sekolah kelas satu, sekolah ini khusus untuk anak-anak priyai dan kaum terkemuka (aristokrat). 2) Sekolah-sekolah kelas dua, sekolah ini diperuntukkan bagi anak-anak rakyat jelata.

Pada masa pemerintahan Sultan Muhammad Mulia Ibrahim Tsafiuddin kurikulum dalam pendidikan Islam bercampur antara pendidikan Islam dan pendidikan umum akan tetapi corak pendidikan Islam masih mendominasi dalam pelajarannya sehingga sekolah Islam pada pada waktu itu dikenal dengan sekolah arab. pelajaran-pelajaran yang diajarkan di Madrasah Al-Sultaniah masih mendominasi yakni ajaran agama Islam sehingga nuansa Islam masih sangat kental dalam sistem belajar mengajar di Madrasah Al-Sultaniyah sampai kepada Madrasah Al-Sultaniyah yang terakhir yakni Tarbiyatul Islam. Madrasah AsSultaniah tersebut adalah sekolah yang dididirkan di lingkungan Istana AlWatzikubillah Sambas yang pengajarannya pun dilakukan dalam lingkungan Istana. Madrasah Al-Sultaniah tersebut didirikan pada tahun 1916.

\section{DAFTAR PUSTAKA}

Ansar Rahman, dkk. (2010). Kabupaten Sambas Sejarah Kesultanan dan Pemerintahan Daerah. Sambas: Dinas Pariwisata Pemerintah Daerah Kebupaten Sambas.

Ahok, P. (1980). Sejarah Pendidikan Daerah Kalimantan Barat, Pontianak : Balai Kajian Sejarah.

Daliman, A. (2012). Metode Penelitian Sejarah, Yogyakarta: Ombak.

Erwin Mahrus. (2013). Sejarah pendidikan Islam, Pontianak : STAIN Pontianak Press

Fahmi, Urai Riza. (2005). Selayang Pandang Kerajaan Islam Sambas, Sambas : Istana Alwatzikhoebillah Sambas.

Juniar Purba. Nukilan Sejarah Kalimantan Barat, Pontianak : STAIN Pontianak Press. 
Notosusanto, N. (2008). Mengerti Sejarah: Penerbit Universitas Indonesia.

Priyadi, S. (2012). Metode Penelitian Pendidikan Sejarah, Yogyakarta : Ombak.

Sjamsuddin, H. (2012). Metodologi Sejarah, Yogyakarta : Ombak.

Gustriyeni. (2014). Peran Syekh Muhammad Basiuni Imran Dalam Mengembangkan Agama Islam di Sambas Tahun 1913-1975. Skripsi Sarjana Pendidikan Prodi Sejarah IKIP-PGRI Pontianak : Tidak Diterbitkan 